\title{
Effect of Pre-Notch on Deformation of Aluminium Square Plate under Free Blast Loading
}

\author{
Ali Arab ${ }^{1, a^{*}}$, P. Chen ${ }^{1, b}$, Yansong Guo ${ }^{1, c}$, Baoqiao Guo ${ }^{1, d}$, Qiang Zhou ${ }^{1, e}$ \\ ${ }^{1}$ State Key Laboratory of Explosion Science and Technology, Beijing Institute of Technology, \\ Beijing 100081, PR China \\ aarabali83@yahoo.com, bpwchen@bit.edu.cn, 'gys009@qq.com, dbaoqiao_guo@bit.edu.cn, \\ ezqpcgm@gmail.com
}

\section{Keywords: 3D DIC, Pre-Notch, Free Blast Loading}

\begin{abstract}
In this paper the deformation and response of the Al square plate with pre-notch under free blasting loading were investigated. The blast loading process is a complex phenomenon, and accurate modeling, the prediction of deformation during this condition of loading is difficult, numerous investigations have carried out on the permanent deformation and the failure of various materials subjected to the blast; however, the transient deformation of plate subjected to the such intensely loaded has been difficult to measure due to the experimental difficulties. Recently, High speed imaging and 3D digital image correlation (3D DIC) have enabled the reliable none-contact measurement of the deformation and strain in various applications. In this research, 3D DIC method is used to study the effects of pre-notches on the dynamic deformation and rupture of thin Al square plates. The displacement and strain fields during the deformation were analyzed by this method. The Al square plate with the thickness of $3 \mathrm{~mm}$ and with different notch geometries were tested under the free blast loading by 20 gr of TNT. Two synchronized high-speed cameras were used to capture the response of the plate with an inter frame rate of 35000 frame/s. The result of test shows that the 3D DIC is a precise method to measure the full-field dynamic deformation of plate. The pre-notch possesses a direct effect on the maximum and final deformation of plate. Based on the result, the deformation occurs in the two stages; in the first one, the plate is deformed due to the shock impulse and all particles are forced to move out-of-plane and provided with initial velocities, and in the second one, pressure wave is vanished and deformation is occurred due to the imparted momentum.
\end{abstract}

\section{Introduction}

Explosion is a major threat for civil structure and vehicle in the combat zone. In recent years, many researches have carried out to improve the protection of the structure and vehicle against the blast. Measuring the deformation of plate subjected to the blast loading is one important task of solid mechanics. These studies can help for better understanding the dynamic response of the plate as well as identification and optimization of the influence design parameters under this harsh loading. However, most researches are only focused on the flat plate. Traditionally, the flat plate used in the structure as blast mitigation. The plate absorbs the explosion energy by either deformation or failure. Chen et al[1] studied the deformation of the circular aluminium plate under the confined blast loading through the 3D DIC technique. Markose and Rao[2] investigated the mechanical response of the $\mathrm{V}$ shape plate under the blast loading. They found that the geometry of plate has a direct effect on the mechanical response of plate. Kumar et al.[3] studied the effect of curvature on the response of plate subjected to the blast loading. Blast produces the shock wave that travelled through the target plate, and when it meets the other surface of the shock wave, gets reflected. The reflected shock wave on the flat surface is higher than incident shock considering the dissociation and ionization of real gases. This reveals that the resistance of plate against the blast is dependent 
on its thickness[2]. However, effect of defect and crack on the response of the plate structure has not been investigated. In the combat situation defects and cracks could be occurred due to the fragmentation and combined blast. Rakvag et al.[4] studied the effect of various geometries of the preformed hole on the response of the steel plate subjected to the pressure pulse loading. However, in these tests, plates experience a large deformation and no localised deformation observed. Aune et al.[5] investigated the response of the steel plate with pre-formed hole subjected to the blast load. Liu et al.[6]carried out the blast experiments on the copper plate with pre-notch.

In this paper effect of pre-notch on the response of metal plate is investigated through 3DDICmethod. The pre-notch with different size and geometry was prepared and tested under the free blast test.

\section{Methodology}

The layout of the experimental setup is shown in the fig. 1 this facility is located in the explosion chamber located in the Xishian campus of the Beijing institute of technology. The plate is a flat square shape with size of $400 * 400 \mathrm{~mm}$, targets assembled to the structure by the steel window frame. After assembly of the plate only $300 * 300 \mathrm{~mm}$ of the plate is under the direct contact of blast shock wave. The pre-notch was made in the centre of plate by thickness $1 \mathrm{~mm}$ and depth of $2 \mathrm{~mm}$. The details of experiments are shown in the table 1.

Before testing, surface of the plate was ground by sandpaper and washed by alcohol to remove all of the oil and dust. After cleaning the surface more than half of the surface of the targets was painted with white color and then speckled with black dots. This surface is used to perform highspeed digital image correlation (DIC) photography during the blast.

The shock wave is generated by the cylindrical shape TNT, the mass of explosive material and distance from the plate for each test is listed in the table 1 . The explosion is ignited by the electrical detonator. The detonator ignite plus is also used to trigger the cameras.
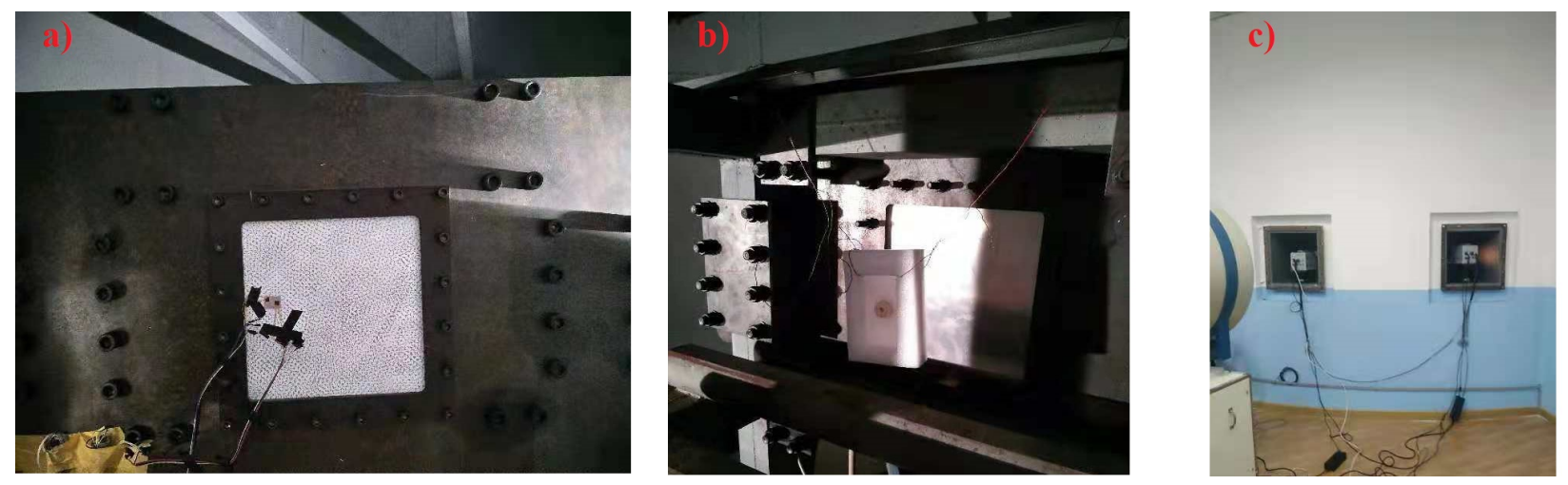

Fig 1. Experimental setup a) front view of the plate b) explosive material at back of the plate c) high speed cameras set up 
Table 1. Dimension of tested samples

\begin{tabular}{|c|c|c|c|c|c|c|}
\hline Sample name & material & $\begin{array}{c}\text { Size of } \\
\text { plate }\end{array}$ & $\begin{array}{c}\text { Size of plate } \\
\text { under the } \\
\text { explosion } \\
\text { loading }\end{array}$ & $\begin{array}{c}\text { Explosion } \\
\text { mass }\end{array}$ & $\begin{array}{c}\text { Explosion } \\
\text { distance }\end{array}$ & notch \\
\hline $\mathrm{Al}-0$ & $\mathrm{al}$ & $40 * 40 \mathrm{~cm}$ & $30 * 30$ & $20 \mathrm{gr}$ & $22 \mathrm{~cm}$ & no \\
\hline $\mathrm{Al}-30-0$ & $\mathrm{al}$ & $40 * 40 \mathrm{~cm}$ & $30 * 30$ & $20 \mathrm{gr}$ & $22 \mathrm{~cm}$ & $\begin{array}{c}\text { Length }=30 \mathrm{~mm}- \\
\text { angle= 0 depth }=2 \mathrm{~mm}\end{array}$ \\
\hline $\mathrm{Al}-30-45$ & $\mathrm{al}$ & $40 * 40 \mathrm{~cm}$ & $30 * 30$ & $20 \mathrm{gr}$ & $22 \mathrm{~cm}$ & $\begin{array}{r}\text { Length }=30 \mathrm{~mm}- \\
\text { angle }=45 \\
\text { depth }=2 \mathrm{~mm}\end{array}$ \\
\hline $\mathrm{Al}-40-0$ & $\mathrm{al}$ & $40 * 40 \mathrm{~cm}$ & $30 * 30$ & $20 \mathrm{gr}$ & $22 \mathrm{~cm}$ & $\begin{array}{c}\text { Length }=40 \mathrm{~mm}- \\
\text { angle }=0 \\
\text { depth }=2 \mathrm{~mm}\end{array}$ \\
\hline & & & & & & \\
\hline
\end{tabular}

\section{D-DIC}

Digital image correlation is a non-contact optical method to study the motion, displacement and strain field. This method consists on capture consecutive images during applying the load to measure and evaluate the deformation and strain field. In this method the surface of the sample should paint by the random speckle pattern[7]. Details on principals and application of the 3D DIC can be obtained in the literature [8-11].

To analyse the 3D deformation of the plates subjected to the blast, two high speed cameras were used. These cameras were set outside of the explosion chamber to protect them from the shock wave of blast. They observe the same area of plate from the bullet proof windows. Cameras were linked and synchronized to each other by means of the synchronising cable that connected the cameras. The 35000 fps was set for both cameras with pixel of (320 568). TTL trigger circuit was used to trigger the cameras and send pulse to start detonation. Three flash lamps were used to provide the enough illumination and avoiding the shading during the test. Before each test the position of the cameras was calibrated with calibration board ( $9 * 9$ distance of 12 ). VIC-3D software was used to analyse the images and to calculate the deformation and strain of the plate. Based on the parameters of cameras and calibration coordination, by matching the reference images of the two cameras, the 3D surface contour of plate before blast can be reconstructed. And displacement and deformation of the plate can be calculated by the correlation, matching the deform images and reference image.

\section{Result}

As shown in the Fig. 2, a part of aluminium plate is selected as an area of interest (AOI) used to measure the displacement of the plate. Due to the limitation in the image resolution, the AOI is smaller than the whole plate size. Fig. 3(a) shows the evolution of aluminium plate without prenotch (al-0) deformation along the vertical line in the centre of plate. After the detonation, the pressure wave travels through the air and arrives at the aluminium plate, creating a transient distributed load. Initially, this pressure is highly localized at the centre of plate. However, for the al- 
0 plate, the maximum deformation in early stage does not occur in the centre of the plate, it could be due to the positioning of the charge, which may have had a small offset from the centre of plate. However, after0.25ms the maximum deformation is shifted to centre. Aune et al. [12] found that the geometry of the plate and boundary conditions had a greater influence than the positioning of the charge on the deformed shape. Fig. 3 (b) shows the out of plate displacement history of the several points on this line. Close to the border of the plate, particles are constrained due to the fixed boundary conditions and only have a limited initial displacement. During the blast loading, all particles of plate are forced to move out-of-plane (z- axis), when the load from the blast have vanished, the plate continues to deform. Spranghers et al.[13]found that the deformation history of plate consists of two parts. In the beginning, deformation of the plate is highly plastic and reaches a maximum value. After the plastic deformation, an elastic rebound occurs followed by elastic vibrations combined with damping[14]. Al-30-45 plate shows the maximum plastic deformation among the all plates. It is observed thatal- $40-0$ and al- 0 plate experienced reversed snap buckling during the elastic rebound.

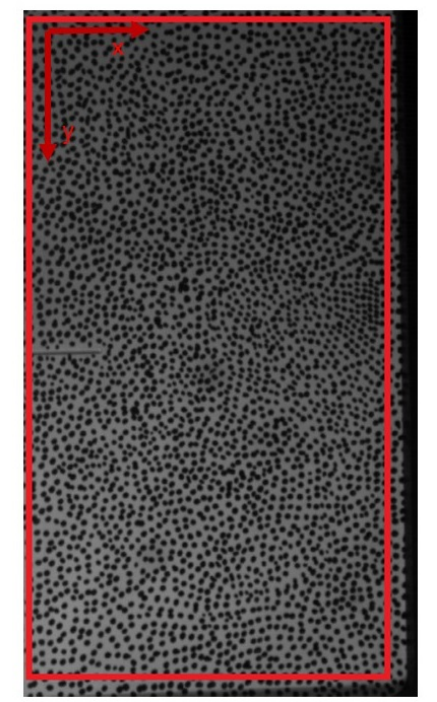

Fig.2 Area of interest (AOI)

Based on the DIC analysis, it can be seen that the maximum strain first occurs in the centre for the al-0 plate, and spreads rapidly outwards to the boundary. For the other plates the maximum strain was occurred at the pre-notch tip in early stage.

After the tests, all samples were collected for further analysis. There were no visible signs of tearing at the boundaries for all plates. For the al-30-45 and al-40-0 plates, it was observed that the cracks wereinitiated from the tips of the pre-notch and propagated. And also, for the al-40-0 plated, it was observed that rupture occurs at the location of pre-notch during the blast loading. 

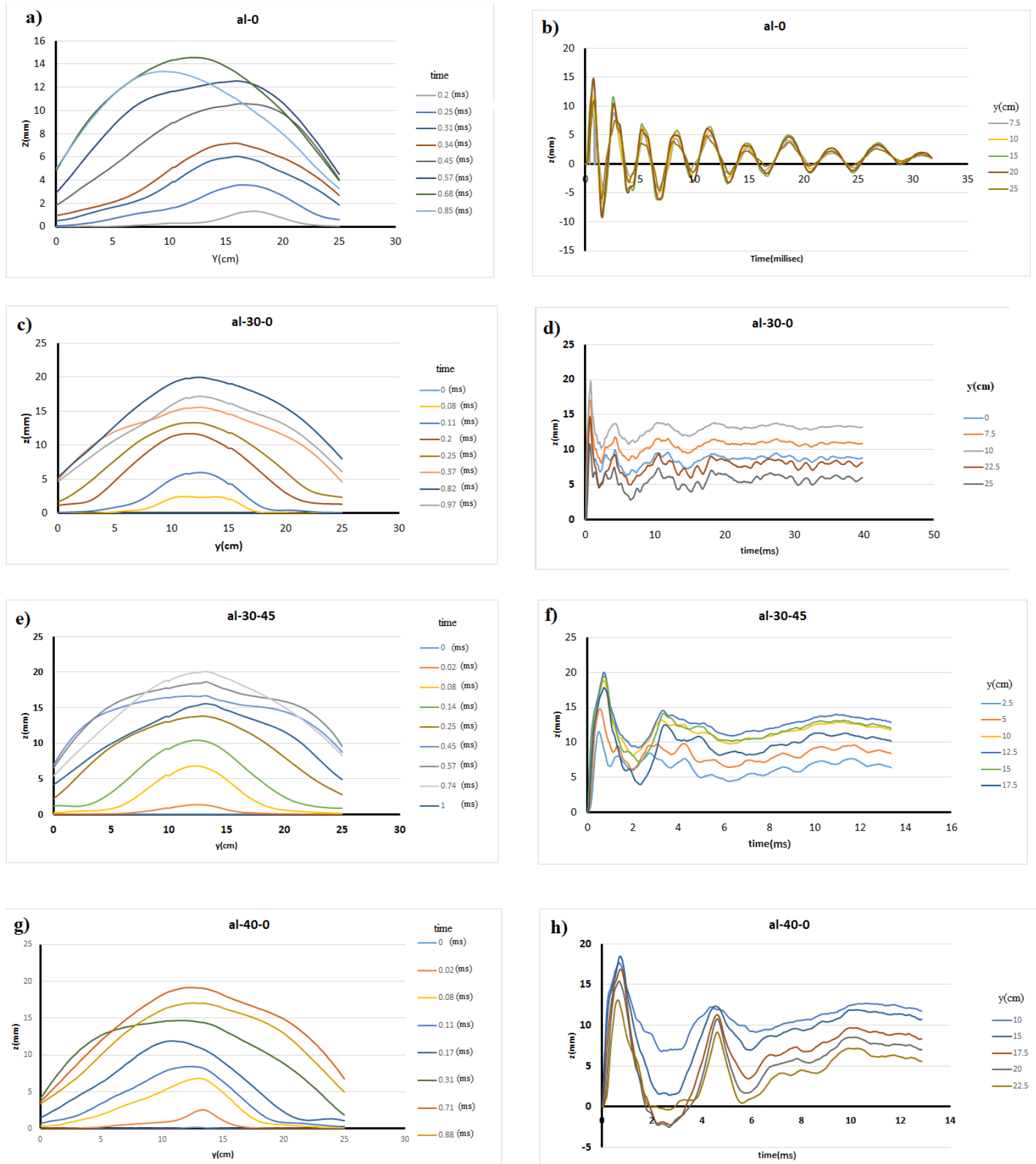

Fig.3 evaluation of the displacement line profile along the vertical section line on the surfaces of a)al-0, b)al-0,c)al-30-0, d)al-30-0, e)al-30-45, f)al-30-45, g)al-40-0 and h) al-40-0

\section{Summary}

3D Digital Image Correlation (DIC) technique was applied to analyzing the response of pre-notched plate subjected to the free air blast. The pre-notched plate experienced the larger plastic deformations compare to the plate without notch. Failure was observed in al-30-45 and al-40-0 
plate. The al-30-45 plate shows the greatest deformation among the all plates. This result shows the pre-notch has great influence on the response of plate to the blast loading.

\section{References}

[1] Chen PW, Liu H, Ding YS, Guo BQ, Chen JJ, Liu HB. Dynamic Deformation of Clamped Circular Plates Subjected to Confined Blast Loading. Strain 2016;52:478-91. doi:10.1111/str.12190. https://doi.org/10.1111/str.12190

[2] Markose A, Rao CL. Mechanical response of V shaped plates under blast loading. Thin Walled Struct 2017;115:12-20. https://doi.org/10.1016/j.tws.2017.02.002

[3] Kumar P, Stargel DS, Shukla A. Effect of plate curvature on blast response of carbon composite panels. Compos Struct 2013;99:19-30. https://doi.org/10.1016/j.compstruct.2012.11.036

[4] Rakvåg KG, Underwood NJ, Schleyer GK, Børvik T, Hopperstad OS. Transient pressure loading of clamped metallic plates with pre-formed holes. Int J Impact Eng 2013;53:44-55. https://doi.org/10.1016/j.compstruct.2012.11.036

[5] Aune V, Valsamos G, Casadei F, Langseth M, B??rvik T. On the dynamic response of blastloaded steel plates with and without pre-formed holes. Int J Impact Eng 2016;108:27-46. https://doi.org/10.1016/j.ijimpeng.2017.04.001

[6] Liu H, Chen PW, Guo BQ, Zhang SL, Liu HB, An EF. Deformation and Failure of PreNotched Thin Metal Plates Subjected to Confined Blast Loading. Appl Mech Mater 2015;782:49-58. https://doi.org/10.4028/www.scientific.net/amm.782.49

[7] Saburi T, Yoshida M, Kubota S. Dynamic strain distribution of FRP plate under blast loading. Int. Congr. High-Speed Imaging Photonics, vol. 10328, 2017, p. 103281N-6. https://doi.org/10.1117/12.2271148

[8] Tiwari V, Sutton MA, McNeill SR. Assessment of high speed imaging systems for 2D and 3D deformation measurements: Methodology development and validation. Exp Mech 2007;47:561-79. https://doi.org/10.1007/s11340-006-9011-y

[9] Hammer JT, Liutkus TJ, Seidt JD, Gilat A. Using Digital Image Correlation (DIC) in Dynamic Punch Tests. Exp Mech 2015;55:201-10. https://doi.org/10.1007/s11340-0149924-9

[10] Ren P, Zhou J, Tian A, Zhang W, Huang W. Experimental and numerical investigation of the dynamic behavior of clamped thin panel subjected to underwater impulsive loading. Lat Am J Solids Struct 2017;14:978-99. https://doi.org/10.1590/1679-78253521

[11] Louar MA, Belkassem B, Ousji H, Spranghers K, Kakogiannis D, Pyl L, et al. Explosive driven shock tube loading of aluminium plates: Experimental study. Int J Impact Eng 2015;86:111-23. https://doi.org/10.1016/j.ijimpeng.2015.07.013

[12] Aune V, Fagerholt E, Hauge KO, Langseth M, Børvik T. Experimental study on the response of thin aluminium and steel plates subjected to airblast loading. Int J Impact Eng 2016;90:106-21. https://doi.org/10.1016/j.ijimpeng.2015.11.017

[13] Spranghers K, Vasilakos I, Lecompte D, Sol H, Vantomme J. Full-Field Deformation Measurements of Aluminum Plates Under Free Air Blast Loading. Exp Mech 2012;52:137184. https://doi.org/10.1007/s11340-012-9593-5

[14] Curry RJ, Langdon GS. Transient response of steel plates subjected to close proximity explosive detonations in air. Int J Impact Eng 2017;102:102-16. https://doi.org/10.1016/j.ijimpeng.2016.12.004 